\title{
A representação de projetos de interiores: o processo criativo e a utilização de softwares 3d
}

The representation of interior projects: the creative process and use of $3 d$ software

\author{
SILVA, Sérgio Gomes da; Especialista; Unicesumar \\ sergio.gomess@live.com \\ PEREIRA, Clauciane Vivian; Mestre; Unicesumar \\ clauciane@globo.com
}

CAMARGO, Larissa Siqueira; Doutoranda; Anhembi Morumbi; Unicesumar larissa.camargo@unicesumar.edu.br

\section{Resumo}

A partir de um breve questionário, 13 profissionais apontaram a maneira como trabalham, indicando, dentre outras coisas: se aplicam ou não uma metodologia criativa específica; quais etapas compõem essa metodologia; se acreditam que a aplicação da metodologia interfere na qualidade do projeto; e se acreditam no aumento do nível de exigência dos clientes quanto ao tipo de representação dos projetos de interiores. Os resultados indicam que a grande maioria dos profissionais entrevistados se preocupa em colocar em prática um conjunto de etapas que antecedem a utilização dos softwares de representação, que a aplicação de uma metodologia está relacionada à qualidade do projeto e que o nível de exigência dos clientes quanto à representação dos projetos de interiores de fato aumentou.

Palavras Chave: representação, projeto, design de interiores.

\begin{abstract}
Thus, from the of a brief questionnaire, 13 professionals pointed out the way they work, indicating, among other things: whether or not a specific creative methodology is applied; which stages make up this methodology; it is believed that the application of the methodology interferes in the quality of the project; And $d$ - they believe in the increase of the level of exigency of the clients as to the type of representation of the interior projects. The results indicate that the vast majority of interviewed professionals are concerned with putting into practice a set of steps that precede the use of representation software, that the application of a methodology is related to the quality of the project and that the Level of customer requirement as to the representation of interior design in fact increased.
\end{abstract}

Keywords: representation, design, interior design. 


\section{Introdução}

O século XXI é marcado pela "revolução digital", desde então, no design ou na arquitetura, a influência dos programas de representação gráfica, os softwares "CAD" (Computer Aided Design ou Desenho Assistido por Computador), tomou conta do mercado de trabalho, tanto positiva quanto negativamente. Antes disso, os projetos eram elaborados manualmente, com o auxílio de instrumentos de desenho, como: lapiseiras, canetas nanquim, régua paralela, escalímetro, esquadros, compasso, transferidor, prancheta, entre outros.

Essa evolução, do manual para o digital, além de simplificar e baratear o processo de desenvolvimento de um projeto,

tem permitido aumentar a gama de meios que podem ser utilizados na expressão de uma idéia. Esse conjunto de fatores tem contribuído com novas possibilidades de criação, visualização e edição de modelos tridimensionais, aumentado conseqüentemente a capacidade de compreensão e análise dos projetos. (FERNANDES ET AL, 2006, p. 38)

Observar os resultados obtidos pelos mesmos profissionais e estabelecer um comparativo entre aqueles projetos desenvolvidos antes e aqueles projetados depois da disseminação dos softwares CAD é um exercício interessante, mas que não necessariamente nos leva a uma conclusão sobre quais mudanças essa nova realidade nos trouxe. Nos projetos de Zaha Hadid, por exemplo, vêse uma evolução clara das formas puras às mais orgânicas, já nos projetos de Thom Mayne vê-se a mesma linguagem e forma de projetar.

Obviamente, um projeto de interiores não se resume ao modo de representação, pelo contrário, o desenvolvimento de projetos segue uma vasta lista de procedimentos como os estudos: do perfil do(s) usuário(s), ergonômicos e funcionais, acerca do layout do ambiente, de estilos e tendências, de cores, de materiais, para a definição de orçamento, entre outros. Essa diversificada lista de saberes e estágios de desenvolvimento de projetos - colocadas em prática pelo designer nos remete ao caminho percorrido para alcançar as expectativas do cliente e, consequentemente, um bom projeto -, em outras palavras, é o que chamamos: processo criativo.

Pensando pelo lado do processo criativo e do desenvolvimento dos projetos de interiores em geral - não pelo lado das questões que envolvem o uso, ou não, dos aplicativos digitais -, este artigo pretende debater, especificamente, a realidade atual dos projetos, dos processos e dos resultados finais obtidos por profissionais da área.

A nova geração de profissionais não passou pelo processo de estranheza da transição do desenho manual para o digital, embora ambas as linguagens sejam realidades conhecidas entre os novos designers e arquitetos, para eles a supremacia dos meios digitais é inegável. A questão, que se mantém atual e na pauta de discussão dos profissionais, docentes e discentes da área, leva em consideração a forma como o processo criativo tem sido colocado em prática na era digital.

Assim, o objetivo deste artigo é conhecer o modus operandi da nova geração de designers e arquitetos. Para que este objetivo fosse atingido, formulou-se um questionário composto por 07 (sete) perguntas cujas respostas podem demonstrar se o profissional se preocupa em colocar em prática um processo que organiza seu raciocínio criativo ou não e, se sim, por meio da exposição do processo criativo adotado, conhecer a relação que cada profissional estabelece entre seu processo de criação e a utilização dos softwares CAD. 


\section{O Caminho até as pedras}

No design de interiores - assim como em qualquer outro setor do design, como a moda, o gráfico, a web, o de produto, enfim -, há a prerrogativa, seja do próprio designer, do mercado de trabalho, da indústria ou do cliente, de transformar um "problema" em "solução".

Embora não fosse um designer, Shakespeare estava certo, há mais coisas entre o problema e a solução do que poderia supor nossa vã filosofia. Munari (2000, p.10), assim como muitos designers, concordando com Shakespeare, sugere que o que há entre o start e o encerramento do projeto é a metodologia do design, "uma série de operações necessárias, dispostas em ordem lógica, que nos leva de forma confiável e segura à solução de um problema".

A metodologia pode ser entendida como sendo o estudo dos métodos. Pode significar o conjunto de etapas a seguir num determinado processo, a partir da análise de vários métodos disponíveis, de suas potencialidades e limitações de aplicação. É o conjunto de ideias e diretrizes que orientam uma investigação.

Assim, ao contrário do que muitos imaginam, as ideias ou soluções para os problemas de design não são instantâneas, demandam um processo (o criativo), uma metodologia ou um conjunto de ferramentas que aplicado ao problema nos leva à eureca.

Dessa forma, ser contratado para desenvolver um projeto de interiores implica transitar por esse conjunto de operações, até que alcancemos o produto final desse processo. Só então entramos no mérito da utilização dos softwares 3D, úteis para a representação de uma ideia. Como corrobora a designer de interiores, Larissa Siqueira Camargo, em entrevista ao jornal O Diário, "enquanto um profissional personaliza, o software apenas ilustra e representa" (CAMARGO apud BERTOLA, 2017, online).

Essa é a real função dos 3Ds, materializar aos olhos do cliente, por meio de desenhos virtuais em 3 dimensões, a solução desenvolvida pelo designer para o seu problema, o que não quer dizer que os desenhos manuais ou as representações físicas, como as maquetes, sejam ultrapassados ou ineficientes, pelo contrário.

Para Fernandes et al (2006, p.40), "o ideal é que o projetista desenvolva métodos híbridos que aproveitem os benefícios de croquis, modelos físicos e modelos digitais, organizados para facilitar a experimentação no processo criativo". Da mesma forma, o desenho manual e, posteriormente o desenvolvimento da maquete física, figuram entre as etapas do processo criativo do designer, os croquis, aliás, são indispensáveis no processo de concepção do projeto, e deixá-los de lado não acrescenta em produtividade ou em resultados mais expressivos e eficientes.

Camargo (apud BERTOLA, 2017, online) explica que "passar a utilizar o software como meio de criação, deixando de lado a realização das etapas prévias do processo criativo que garantem um projeto de melhor qualidade, é um erro, já que as ferramentas, por si só, não substituem a expertise do profissional". 


\subsection{Como o mercado recebe os projetos 3D}

A mesma evolução que trouxe aos designers a possibilidade de utilização de uma nova linguagem para a representação de seus projetos trouxe consigo uma avalanche de informações aos que estiverem dispostos a acessá-las. Isso fez com que na atualidade o contratante acompanhe os tipos de projetos oferecidos e tome conhecimento acerca dos softwares aplicados ao desenvolvimento do projeto. Esse interesse por parte dos clientes, de certa forma, permite a valorização do profissional no mercado de trabalho, mas também faz com que este mesmo profissional tenha que se readequar constantemente ao nível elevado de exigência de seus clientes, já que a grande maioria já não pode ser considerada leiga.

Pode-se dizer que muitos clientes passaram a escolher seu designer justamente pelo estilo de projeto, e assim investir em representações gráficas e apresentações cada vez mais realistas, é uma escolha que deve figurar entre as habilidades que o profissional oferece ao mercado. Embora esta não seja uma regra, visto que existem profissionais que possuem ótimas técnicas de representação, mas projetos que não conseguem atender as reais necessidades do usuário, assim como questões relacionadas ao conforto ambiental, a ergonomia e a funcionalidade, entre outros.

Sobre este aspecto, para Camargo (apud BERTOLA, 2017, online), "o uso de softwares pode ser desvantajoso até para profissionais que, por algum motivo, optam por trabalhar com ferramentas que prometem entregar soluções, e se apoiam somente nisso", sem se preocupar em desenvolver outras habilidades e diferenciais. Assim como em outras áreas do conhecimento, também no design, quanto mais capacitado o profissional, mais chances ele tende atingir o seu objetivo.

\section{A PESQUISA}

A pesquisa cujo objetivo é conhecer o modus operandi da nova geração de profissionais apresentados ao mercado anualmente foi realizada na primeira quinzena do mês de março do ano de 2017, via e-mail com 13 profissionais, entre designers de interiores e arquitetos.

Importante ressaltar que a solicitação de preenchimento foi encaminhada a grupos do facebook relacionados à profissão, onde mais de 2000 profissionais são cadastrados. Além disso, foram enviados e-mails direcionados a cerca de 50 profissionais. Mesmo após essas ações, apenas 13 profissionais, que atuam na área de interiores, retornaram a solicitação.

Considerando a quantidade de retorno de interesse no preenchimento, optou-se por um questionário de perguntas abertas, já que a análise seria de fácil resolução, visando uma maior possibilidade de resultados, e, inclusive, apontamentos e informações diferentes das esperadas. Essa abertura foi interessante considerando que os profissionais não sofreram qualquer tipo de influência para as suas respostas.

No questionário, bastante sucinto, constam 7 questões, conforme o quadro que segue: 


\section{QUESTIONÁRIO DA PESQUISA}

Qual seu nome?

Atua em qual cidade e estado?

Qual a sua formação?

Por qual instituição de ensino concluiu sua graduação?

Há quanto tempo atua no mercado?

Como representa os projetos de interiores, por meio das ferramentas de desenho manual ou digital?

Você acredita que os clientes se tornaram mais exigentes em relação ao tipo de representação de projetos de interiores?

Você segue alguma metodologia criativa para desenvolver os projetos de seus clientes?

Cite as etapas na ordem em que as aplica, caso utilize alguma metodologia criativa.

Em sua opinião, a aplicação da metodologia interfere na qualidade do projeto.

Fonte: autores

As cinco primeiras perguntas serviram apenas para traçar um perfil dos profissionais pesquisados, e não foram contempladas nas análises realizadas na atual pesquisa. Os profissionais que responderam aos questionários eram de diferentes estados brasileiros, porém, contemplando basicamente a região sul e sudeste do país, salvo a participação de uma profissional do nordeste. Assim, a pesquisa foi realizada com os profissionais dos seguintes estados:

- 5 Paraná

- 3 de Santa Catarina

- 1 do Rio Grande do Sul

- 3 de São Paulo

- 1 Rio Grande do Norte 


\section{RESULTADOS}

Com todas as respostas aos questionários em mãos, primeiramente, relacionamos para encontrarmos os padrões de informações. Percebeu-se que, mesmo com perguntas de respostas abertas, a familiaridade de respostas era bastante presente, o que, inclusive permitiu que trabalhássemos com gráficos com apenas dois padrões comparativos.

Como citado anteriormente, as primeiras cinco perguntas não terão suas respostas apresentados nos resultados, considerando que estas informações não são necessárias para o objetivo em questão. Desta maneira, serão apresentados os resultados das perguntas de 6 a 10, em porcentagem, como uma análise, tendo como base os objetivos da pesquisa. A seguir serão apresentados os dados e a análise dos resultados alcançados a partir da realização das entrevistas com a amostra de treze profissionais.

Quando perguntados sobre como representam os projetos de interiores, apenas um entrevistado, ou seja, $8 \%$ do total disse utilizar o desenho manual, enquanto o restante - $92 \%$ utiliza o desenho digital ou os softwares CAD. Ainda dispomos de um profissional que representa os seus projetos de interiores por meio manual, considerando que todos os profissionais entrevistados estão no mercado atuando, percebemos que ainda é possível à entrega dos projetos aos clientes representados manualmente.

Gráfico 1 - Como representa os projetos de interiores, por meio das ferramentas de desenho manual ou digital?

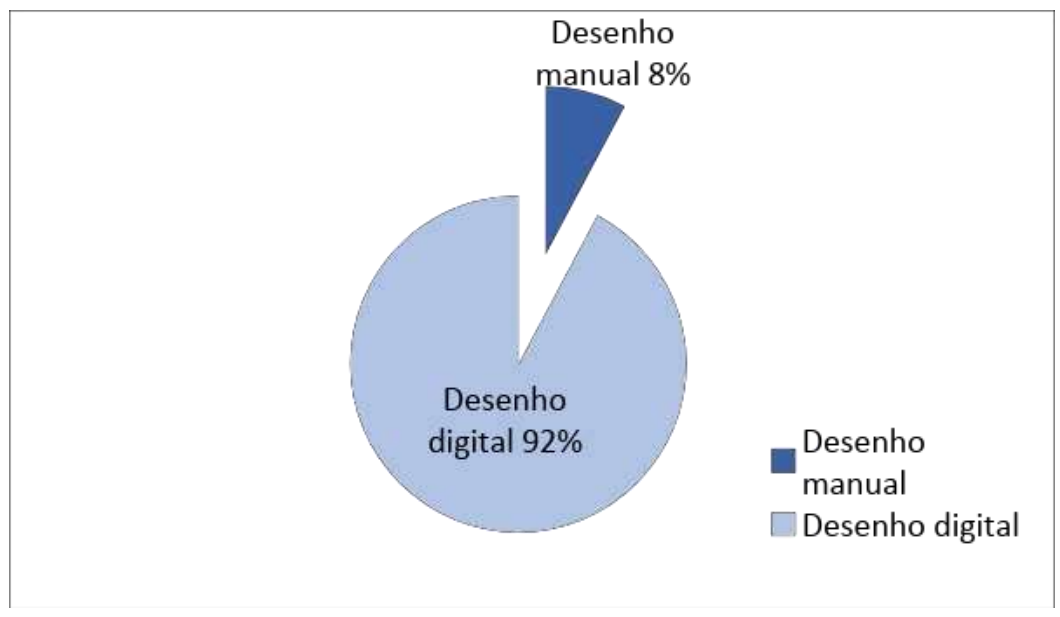

Fonte: autores

De qualquer modo, esse resultado reafirma que atualmente a utilização dos softwares 3D para a representação de projetos de interiores é cada vez mais comum, quase que inevitável, considerando que as demandas do mercado acabam por exigir que os profissionais estejam atentos às evoluções das imagens representadas digitalmente. Isso se confirma ainda mais com o resultado que será apresentado no gráfico a seguir. 
Gráfico 2 - Você acredita que os clientes se tornaram mais exigentes em relação ao tipo de representação de projetos de

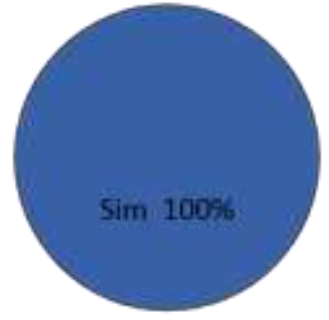

interiores?

Fonte: autores

Questionados sobre o possível aumento do grau de exigência sobre o método de representação, os entrevistados foram unânimes, concordando que o mercado passou sim a ser mais exigente em relação às imagens que representam as ideias e projetos. Essa foi a resposta, inclusive, do profissional que ainda faz as suas entregas em desenhos manuais. Assim, pode-se afirmar que a valorização do mercado é real e que a utilização dos meios digitais de representação de projetos passou a ser uma alternativa, ou, talvez a causa, dessa situação, deixando de ser um diferencial para o designer, passando a ser cada vez mais exigida pelos clientes.

Considerando que a importância da representação mais realista de um projeto é uma valorização unânime, e que, quase todos os profissionais utilizam os meios digitais para os seus projetos, entramos nas questões metodológicas, mais especificamente relacionadas aos processos criativos, questionando os profissionais quanto a utilização de alguma metodologia criativa para o desenvolvimento dos projetos. De acordo com a pesquisa, como mostra o gráfico na sequência, $39 \%$ dos entrevistados disse que não utilizam qualquer metodologia, enquanto mais da metade dos treze entrevistados $-61 \%$ - disseram que sim, aplicam uma metodologia. 
Gráfico 3 - Você segue alguma metodologia criativa para desenvolver os projetos de seus clientes?

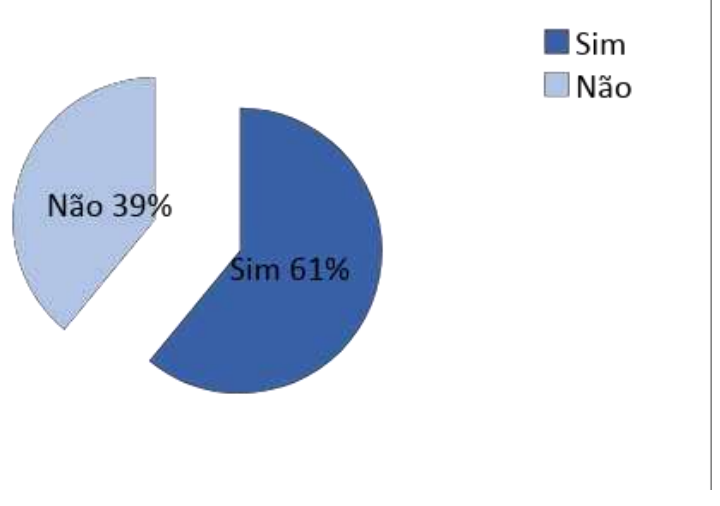

Fonte: autores

A questão seguinte solicitava que os entrevistados citassem as etapas metodológicas que aplicam em seu processo criativo, e assim, foi a que apresentou a maior variedade de respostas. Para a análise, compilamos os resultados, e os registramos de acordo com as ferramentas mais utilizadas e comuns na área do design e de arquitetura de interiores. Assim, 61\% dos entrevistados que afirmaram aplicar uma metodologia criativa apontaram o uso de diferentes etapas, mas de maneira geral, foram consideradas as etapas: briefing, estudo de layout, estudo de cores e elementos do design, análise de correlatos, produção de croquis, entre outros, e só então a utilização dos softwares CAD para a representação do projeto.

Para finalizar, a esses mesmos profissionais foi perguntado: Em sua opinião, a aplicação da metodologia interfere na qualidade do projeto? Sendo que, todos aqueles que afirmaram aplicar uma metodologia criativa, mesmo que própria (61\%), confirmam a interferência nos resultados e qualidade do projeto.

Gráfico 4 - Em sua opinião, a aplicação da metodologia interfere na qualidade do projeto?

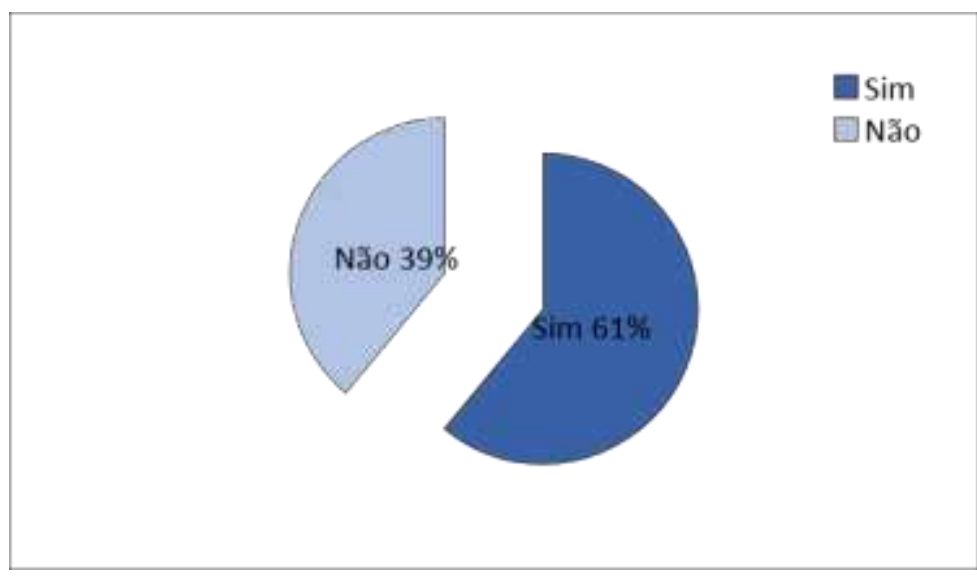

Fonte: autores 


\section{CONSIDERAÇÕES FINAIS}

A partir da leitura desses dados pode-se concluir que entendendo a importância do processo de conceituação e concepção de um projeto de interiores, há aqueles profissionais (61\%) que respeitam os caminhos que conduzem à solução de um determinado problema de projeto, levando em consideração a coleta e análise de informações; a busca de correlatos, por novos materiais, técnicas e processos; a ergonomia e funcionalidade dos espaços; o bem estar e segurança dos indivíduos e o próprio design, utilizando os softwares como aliados para a representação de suas ideias e não como ferramenta criativa. Além disso, esses mesmos $61 \%$ reforçam a importância da metodologia criativa como uma ferramenta cuja função, dentre outras coisas, e como sugere Munari (2000), é nos levar de forma confiável e segura à solução de um problema, consequentemente atendendo as expectativas e necessidades do cliente.

Com o objetivo de conhecer o modus operandi da nova geração de designers de interiores e arquitetos, este estudo se propôs a entrevistar uma amostra de 13 profissionais, cujas respostas apontaram que a maioria dos entrevistados se preocupa em aliar um processo metodológico e criativo próprio para o desenvolvimento de projetos de interiores e que só então, com os conceitos do projeto bem delineados, passam a colocar em uso as ferramentas de representação capaz ilustrar ou materializar graficamente sua ideia. Os mesmo profissionais ainda reafirmar a importação da aplicação de um processo criativo próprio para a qualidade das ideias que apresentam aos seus clientes, afirmando que quando não há a preocupação com o processo de conceituação e concepção de uma ideia os resultados alcançados ficam aquém das expectativas de qualidade do cliente.

O tema aqui discutido, atual e recorrente e, por esse motivo, pode ir além, com a criação de disciplinas para cursos de design de interiores que unem teoria e prática na utilização dos softwares, pode-se explorar também materiais de pesquisa deste campo de atuação, como artigos que possam pontuar e esclarecer os fatores positivos e negativos quanto a aplicação das ferramentas de representação de projetos, auxiliando a futura geração de designers de interiores.

A utilização dos softwares para a representação de projetos de interiores tornou-se uma ferramenta obrigatória, eficiente e produtiva, se for utilizada da maneira correta levando em conta todos os princípios do design, desde aplicação da metodologia até a aplicação de normas técnicas. 


\section{Referências}

ALVES, Medeiros Gilfranco; 0 desenho analógico e o desenho digital: a representação do projeto arquitetônico influenciado pelo uso do computador e as possíveis mudanças no processo projetivo em arquitetura. IV Projetar: projeto como investigação - ensino, pesquisa e prática. São Paulo: 2009. Disponível em: <http://repositorio.cbc.ufms.br:8080/jspui/handle/123456789/1461> Acesso em: 15 mar. 2017

BERTOLA, Fernanda. Muito além dos aplicativos. O Diário, Maringá, 2017. Disponível em: < http://maringa.odiario.com/imoveis/2017/01/muito-alem-dos-aplicativos/2319653/>. Acesso em: Acesso em: 15 mar. 2017

CHING, Francis D. K. Representação gráfica em arquitetura. Porto Alegre: Bookman, 2011

DIANA, Tatiana Borgonovi. O desenho do projeto de arquitetura e sua produção atual. 2012. Dissertação (mestrado) - Tecnologia da Arquitetura - FAUUSP, São Paulo, 2012

DEPOLI, Jacksson. A representação gráfica em arquitetura: uma transição 1979 - 2009. 2009. Monografia (Especialização) - SERVIÇO NACIONAL DE APRENDIZAGEM COMERCIAL, Curitiba, 2009. Disponível em: < http://doczz.com.br/doc/703172/a-representa\%C3\%A7\%C3\%A3o-gr\%C3\%A1ficaem-arquitetura>. Acesso em: 15 mar. 2017

GONÇALVES. Juliana. Designer 3D tem mercado cada vez mais promissor. Bonde, Londrina, 2016. Disponível em: <http://www.bonde.com.br/economia/tecnologia/designer-3d-tem-mercado- cadavez-mais-promissor-423490.html> Acesso em: 15 mar. 2017

MUNARI, Bruno. Das coisas nascem coisas. 2a ed. São Paulo: Martins Fontes, 2000.

ORCIUOLI, Affonso. Projeto assistido por computador: ontem, hoje e amanhã. Revista aU. São Paulo, Edição 197, 2010. Disponível em: http://www.au.pini.com.br/arquiteturaurbanismo/197/projeto-assistido-por-computador-ontem-hoje-e-amanha-181405-1.aspx. Acesso em: 15 mar. 2017

RIGON, Matheus José; BASTIANI, Jamile de; SCHERER, Christine Martins. Entre a imagem e o objeto, o manual e o digital: a representação em uma experiência acadêmica de projeto arquitetônico. Disponível em: < https://www.unochapeco.edu.br/static/data/portal/downloads/2535.pdf>. Acesso em: 15 mar. 2017 